\title{
Exclusive Needs, Inclusive Services
}

\section{Bernard Schaffer}

It is possible to think of choices in favour of meeting basic rather than other needs which have been part of debates within programmes of service or action. Analysis of those choices is not a matter of listing a favourite number of 'needs' (say five), measuring them and then attempting to quantify some total (as, for example, a total of 'housing deficits'). It is seeing what is involved in actual choices as they are presented and as they work out.

It is also that almost any choice or line of action tends to continue to include some and exclude others: one person's need for technological improvement is another person's exclusion from customary employment. There are also problens in institutional action: it is difficult to include and integrate existing and particular concerns within an overall programme of research, planning and administration. A slogan to "Feed, Clothe, House" the nation (as in Guyana after 1973) comes to mean (via import controls) an assault on the customary, deeply entrenched and (in that sense at least) basic diet of one community rather than another. The provision of basic shelter through self-help housing excludes those who cannot meet conditions of residence, employment, stability and physical inputs. This becomes part of the explanation of the whole problem.

Let us look first of all at the reality of such choices. The question then is in part the meaning and appeal of what is basic. We can examine two instances in which this was faced. One example was the Third Indian Public Service Pay Commission which made a specific effort to calculate the minimum subsistence needs of a peon as the base grade of the service, cost the basket and structure the whole classification system accordingly. The difficulty was, apparently, that it would have put the base grade at too high a level on which to build up the pyramid of relativities and advancement which a public service is supposed to require. Preparatory and post-colonial services were already flattening thesc pyramids ', as the extreme racial distinctions and favouritism of colonial administration were, to an extent, removed. There had, it seemed, to be a limit, or so it was argued.

A second exanıple, a little older, is from the first visit of a World Bank mission to Papua New Guinea in

1 Paul Renne]l, "The Historical Legacy of Colonial Civil Service Salary Structures in Angloplione Afriea: A Case Study'. IDS, January 1978 , nimen.
1964. The then colonial (Liberal Country, viz. conservative) Australian administration was explicitly in favour of what we might now recognise as a basic needs strategy: "broadening the base by the establishment of new schools"; viz. covering the whole country with at least a minimum of formal education. The Bank recommended the opposite choice: "making the full course available in existing schools"; a deliberately exclusive, or as its critics said, elitist strategy ${ }^{2}$. The Bank called this its "principle of concentration", which may be taken as an appropriate label for the case against basic needs ${ }^{3}$.

To say, however, that such choices have sometimes been 'real' is not the end of the matter. There are two other features to be looked at. The first concerns the ways in which a choice in favour of basic needs could be conservative, with all that inplies. That is to say, it might well strengthen the forces keeping intact or preserving a system as it is. Either 'concentration', as in one case, or 'sustaining differentials', as in the other, could be interpreted as instruments of change. The opposite is, indeed, perhaps a reinforcement of what is felt to be entrenched, customary, deeply structured, profoundly held or possessed. An expression of basic need, in so far as it implies a 'right' (that is an effectively recognised claim) is in the strict sense of the word tending to the incluctable: a highly seventeenth century notion, Lockeian, later Jeffersonian. I do not rchearse here the degree to which that sort of perception has been revolutionary or reactionary. The record is complex; our interpretation is never disinterested.

Our first difficult task is then to work out the 'politics of basic needs': in what sense is this dimension conservative, in what sense radical? Furthermore in what ways can the 'basic needs' dimension be expressed in processes of rational calculation and political choice; what types of outcome are such processes likely to have? The dominant techniques to aid rational calculation in policy choice are not easily employed to express the case for the 'basic', the 'distributive', etc. Familiar factors have led to the articulation of a case for considering distributive, even basic needs as well as growth and that sort of economic rationality in public policy decisionmaking. The environmentalists tell us not simply to assume that we should go ahcad and exploit a mine: think of other effects. It is easy to assist the

\footnotetext{
2 Ecomomic Debelepmest of the Terrietry of Papua Nen' Guines, Johns Hopkins and Oxford University Press. 1965

3 Compare the contenunorars discussion by Dennis Austin in Folitics in Ghuna, 1946-60, 1964
} 
progressive farmer; but should we not attempt to channel aid directly to the rural poor, and so on. However, the difficulty is then to recruit aids to rational calculation which will provide quantifications of these other welfare considerations which are to be taken into account. Despite roots in welfare economics, most of the available techniques, like cost benefit analysis, perhaps inevitably express individualistic rationalities.

Existing techniques of calculation also tend to reinforce apparently attractive depoliticisations of public policy decision-making . In part they do so because of the fundamentals of calculation. The attempt to aggregate and add individual preference functions obscures political relations, by presenting them as objective and apparently non-conflicting. Considerations like the 'will to pay' and the inclusion of some (and therefore the exclusion of other) participants have the same effect.

A restatement of the inevitability of politics in public policy decision-making is needed. We need to recognise the latent presence, and therefore the need to make more manifest, the opposition of choices and to encourage the mobilisation of forces to assert the interests of those who were in fact excluded in order to counter the individualistic rationalisations and the inescapably anti-welfare or anti-distributive premises of such calculations. Leave to others defence of cost benefit analysis; a correction of inescapable conflicts over values, preferences, experience, calculation, information and commitment in public policy processes; reassessment of the role of aids to calculation.

The force of any political recruitment, however, in favour of the case for the basic and the excluded, (as against hierarchy, differentials, the concentrated and the 'progressive') might well be widespread precisely to the degree to which it represents or voices what is basic politics: has, that is to say, a necessary element of the populist, as cost benefit analysis has of the individualistic. To that extent, the populism of a basic needs politics can reinforce the reactionary, as indeed the populist, if freed from other types of ideology, has always tended. In a choice between the rational economics of individualistic progress and the manic instincts of the populist politician, where should one stand?

Another way of putting this is to ask what the politics of basic needs actually demands and what it may come to mean. This is related to the rival themes behind claims : is the claim in fact a defence of some things as they are, or on the contrary a demand for

4 For a fuller statement,P. J. O. Self, Econocruts amd the Policy Process, 1975: Schaffer. 'On the Politics of Policy', Australian journul of Politis and History, 23, 1, April 1977. especially pp. 151-152. crucial choices and distributive changes? A choice in favour of basic needs, moreover, is supported only with difficulty by the normal use of dominant aids to rational calculation. Hence basic needs choices are likely to depend on an evident politicisation (even a re-politicisation) of public policy decision-making processes. However if the case for basic needs (as in Papua New Guinea: spread minimum education inclusively) is to depend on a more political expression (since cost benefit analysis cannot be relied on), political mobilisation around a basic needs programme might work out, as things have a habit of doing, rather oddly.

The first point about the reality of a choice for basic needs is the complexity of its political meaning. There is a second: there is nothing especially new in thinking about the problems of the minimum. The history of ideas and policies leading to the Beveridge welfare state is a case in point: the iron law of wages and Poor Law reform; a harsh state minimum and a charitable option; trade union difficulties about the minimum and the differential; the persistence of poverty at or below the minimum; the criticisms of Illich. Classical political economy (Bentham, Chadwick and Nassau Senior) demanded punitive measures in relation to the persistent poor. So the 1834 Royal Commission on Poor Laws attempted to abolish the outdoor relief of the Speenhamland System altogether. Outdoor relief after all was held to have corrupted the natural forces which would abolish poverty through their effects on income level and population. The burden of taxation for the Poor Law was held to debase wages and investment, and it created an alternative to the 'natural' minimum rate of subsistence. So outdoor relief was actually the cause of poverty; abolishing it would abolish poverty 'in the end'; in the interim a harsh and punitive poor law (the workhouse) was absolutely necessary. In an evangelical age its very harshness needed some normative justification. The distinction between the 'deserving poor' who should be eligible for softer measures of charity (something above the minimum or basic) rather than harsh measures of state action, and the 'undeserving poor' who therefore only 'deserved' what they got from the 1834 system (the very basic minimum) suited this normative need admirably ${ }^{5}$.

This position broke down through two main forces. Booth and Tawney on through Bowley and Spring Rice revealed the association of poverty with permanent, recurrent, structural and inescapable facts, like age, sickness, the conditions of working class motherhood, sweated wages and long term unemployment. These were either facts of economic

\footnotetext{
5 S. E. Finer. Liffe and Times of Sir Edwin Chadwick, London.
} Methuen. 1952: and Charles Dickens. 
change and social inefficiency in housing and sweated wages, or of personal and family life which could not be deilt with, like the cost of sickness. Minimal provision would not remove these causes, even 'in the end'.

The second force was the extension of trade union organisation beyond crafts and artisans to general labour and women. This was associated with the revolt against charity. The deserving poor did not think much of what they got, and the undeserving poor seemed to be the sick, the elderly and the mothers. Neither the basic minimum nor the charitable amelioration seemed quite right.

This change brought certain problems. In the first place the impact and the political attitudes of working class and trade union organisation on poverty itself had not been consistent. High standards for some, a maintenance of differentials and an equalisation which neglected the lower percentiles had been the order of the day. Contrast, for example, Tawney's statements with Galbraith's sour words ${ }^{6}$. The point once again is that extreme poverty--the "lower percentiles'--leads to isolation: that is, it tends to create dependence on hand-outs. The process of delivering hand-outs 'individuates', isolates, ilienates the recipient, as political action and the social relations of work tend on the contrary to create solidarity. Once people have been isolated like this, their isolation allows stereotyping to operate. We then see in the history of ideas and of public policy a variety of explanations which tend to justify things as they are. Classical liberalism and charity provided some; social science has provided others (problem families and case work); political science and political sociology offer further examples and socialism others (the lumpen proletariat).

Furthermore, the actual measures both of clissical political economy and liberalism and welfare state socialism seem to have had little effect on the persistence of a poverty percentage: the submerged 10 per cent in developed socicties. Compare the percentage on poor relief in the 1830s with those dependent on the Supplementary Benefits Commission in the 1970s: both approach 10 per cent. Poverty as a pattern of distribution within developing societies and as an international factor are simply other examples of this persistence. Hence alternative explanations have emerged, like Illich's own implication that classicial poverty would disappear were it not for an artiticial, 'modernised' sense of deprivation (false deprivation as a sort of false consciousness?)

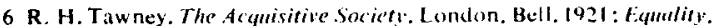
London. Allen and Unwin. 1931; and J. K. Galhrath. The d/fhrent Suciet, Boston. Houghton. Millin. 1958.
This reveals the difficulties. There is an inherent, almost inescapable tradition of thought which is in favour of state action or private charity to ensure a minimum, with optional individualistic choice for anything above it. The institutionilisation and impact of charity, and the problems of inclusion and exclusion are rarely understood. Beveridge did better: the minimum was to be statutory, not charitable, but essentially inclusive and nondiscretionary. Further, the minimum, basic, quasiinclusive was not, as it were, about the sectors in which choices (e.g. for more than basic education) could operate or perhaps be met, but about some (basic) as against other (non-basic) needs. The conditions of access, like queuing for what was nonurgent could, in so far as they were understood, be accepted in that sense as an alternative to market options.

Britain came nearer to a satisfactory solution by the inclusive nature of War damage? The bombs fell indiscriminately. Anyone might find himself with an urgent need for immediate relief, even compensation. All classes found themselves encountering public administrative agencies distributing emergency payments. Only the existing Assistance Board local offices (ironically remnants of the Poor Law) had the distributive network and the apparatus to manage this. The encounter between the middle classes and these agencies changed the classes, the administration and social understanding: these classes demanded a different style of treatment which only inclusiveness of coverage and provision could have achieved.

Why can we not just say, then, that a new Beveridge Report is the basic human needs strategy we are looking for? Part of our answer in brief is, in fact, that Beveridge and welfare state Fabianism, as Herman Finer said, "assumed public administration". That is, it assumed that public administrative agencies, the processes of organisation, were merely neutral (or even benevolent) and at worst more or less efficient instruments. A blunt knife might need sharpening; it would not make you a vegetarian. This is what we have come to question, especially about Beveridge, but also in all distributive programmes. The actual rules and institutions of the distributive processes are highly problematic: they cannot just be ignored or alssumed away. The significance of their effects, however, is especially heavy where the programmes are supposed to be distributing basic needs (e.g. low cost shelter, minimal food rations) to those orherwise excluded (e.g. marginal rural-urban migrant families). That is, the rules and institutions are exceptionally difficult for them to handle (e.g. with conditions of residence and documentation).

7 Richard Titnuss. Problems af Social Policy, 1950. passion. 
Hence, in basic needs programmes, it is above all essential to consider these distributive problems: but how is that to be done?

The most crucial problem is in fact the very exclusion itself: not merely the exclusions of the dual mandate or the dual society; the exclusion from growth; but the exclusion from these developing services of the formal and urban sector. Now the concept of exclusion is open to discussion, in part because it is the process of exclusion which makes benefits to the included possible and desirable. Failure to consider the relationship between exclusion and inclusion, moreover, creates difficulties for the theory of collective or public goods in which consumption is supposed not to diminish supply so that there is no need either for pricing or for conditions of access ${ }^{8}$. The air to breathe is, indeed, a basic need. It can be free because the supply does not diminish as the number of people breathing increases. It can be freely available (without intervention of programmes and agencies) for similar reasons. So goes the theory. To state it is to explicate its inadequacy.

This makes the objective facts of exclusion more, not less, open to criticism. We think of the need to tackle the currently fashionable argument for 'saving' the 'welfare state' by making inclusive services again only minimal. Meanwhile the political dynamics of integration in post-colonial states make the objective exclusiveness of public programmes normatively, and therefore from time to time actually, unacceptable. At least exclusiveness becomes a negative evaluative criterion and a cause for action ${ }^{9}$.

If a basic needs strategy means anything it means dealing with exclusion of areas, of people, of needs. It is provoked not by lists and categories but by this sort of record. Unfortunately this sets up certain further inherent difficulties. The very facts of exclusion from basic needs, the combinations of peripheralisation of need, person and area with more or less political voice, induces a resort to programme and project. That is, where these potentially 'alienated', stereotyped, 'lower percentiles' do in fact manage to exert a group claim, their very maltreatment and exclusion from existing 'normal' distribution (the housing market, e.g.) seems to imply the creation of non-normal, unusual, specific measures. Hence schemes for 'marginal farmers' and '(landless) labourers'. This sets up a process of institutionalisation which is in part a matter of budgeting and of organisation building. This often amounts to new institution-building, since it had

8 See the contemporary work by Fred Hirsch.

9 G. D. Wood, 'Rural Development in the Post Colonial State: Administration and the Peasantry in the Kosi Region of North East Bihar", Develomment amd Change, 8, 3, 1977 been the failure, that is the evidently basic exclusiveness of the existing institutions which induced the new "inclusive" basic programme. It also sets up institutional rather than other types of distribution and allocation, since again the existing distributive processes (marketing especially) somehow seem not to have worked. Rural services were not being extended, inputs were not available.

On that track, instrumentation and itemisation take over: rules of eligibility, priorities and definition of the service item which is now to be extended in response to the expression of exclusion from basic need as far as the routines of rinstitutional distribution are concerned, and the detection of failure or 'problem' (a different point) in policy discussions. The actual methods of distribution, its instrumentation, have to be devised: e.g. the definition of the papers, etc., which will have to be presented to demonstrate eligibility for the category cif person, need or area to be assisted; the setting up of waiting lists and so on. And then, equally, the definition and allocation of the actual item of service itself: a temporary road job, a tower block top floor flat, a ration of rice inside an encampment. The item of service eventually provided may be some distance from basic needs and the background reality to the claims of the excluded to these instruments and service items.

This irony of institutional response to institutional failure has aspects which we have shown elsewhere ${ }^{10}$. But the position of the people and areas excluded from "basic needs" and the instrumentation of distribution itself are exactly the factors which aggravated just those difficulties in the first place: of handling bureaucracies; of physical access; of tining; and of the dissonance of need and service item.

We now see more clearly than ever that the institutionalisation of distribution does not merely fail to meet those scarcities and exclusions which excite basic needs programmes in the first place. It is actually the source of the situation itself in at least two ways. One is the type of policy or problem definition which institutional programme planners are committed to. These are essentially problems of addition, supply and overall deficit as distinct from peripheral distribution and allocation.

The second point is that there are processes in institutional distribution which themselves create new exclusions and scarcities: bureaucratic costs;

10 Schaffer. 'Official Providers: Access, Equity and Participation' Reports/Studic's EQU.1, Unesco Division for the Study of Development, Paris 
limitations of official time; imposition of extrinsic standards; allocation of public rights to some, creating new costs and structures for others. Furthermore, we also now see that this works its way through hard as well as soft sectors. The evaluation of highway and power projects has made this clear. As Percy Selwyn's article in this issue shows, the use of subsidies in public service has widespread costs and only selective benefits. All contribute, only some gain access. It is the levels of cost working with the processes of exclusion which create the difficulty.

These two points need some emphasis. Institutional policy makers have to work to the sorts of problem which they can handle, or, more strictly, which they can manage but not quite solve (so that their 'basic need', the maintenance of their role, is not challenged). These tend to be aggregate concepts like housing deficits, and technical and instrumental solutions like construction programmes and point allocation systems. The implication is that little more, or less, can be done. The eye is turned away from the initial need, and its domain of action. Secondly, the allocative procedures themselves, ironically enough, set up new costs, new exclusions, new scarcities, new inequalities, new stratifications.

But that is not to say that a choice or concern for basic needs is unreal. We have argued that it is real but complex. In particular, a basic human needs strategy means nothing unless it faces these problems of distribution and allocation, of inclusion as against exclusion, which excite the concern in the first place. The formulation of such strategies, however, has to involve non-Utopian solutions. Discussing the possibilities would need another paper. It would partly express a concern with the evidence of institutional costs and of the institutionally excluded: 'degraded' exit and access, as Geoff Lamb and I have called it elsewhere ${ }^{11}$, and would partly be an explication of the inter-relation of basic service provision with employment, income and locational changes. Service provision of itself, especially in basic needs, tends to failure, exclusion, misallocation

11 Schaffer and G. B. Lamb، 'Exit, Voice and Access', Social Science Information, Xill, 6. 1974 and institutional dependency. There are also points to be made about institutional processes themselves, in administrative planning and evaluation, and, in particular, in the possibilities of 'low-profile' low cost alternatives to orthodox institution-building.

Some further implications would include the comparison of fiscal with rationing measures and the extension of the ideas of income guarantee and minimum wage to new conditions. All, however, fundamentally would have to do with the improvement in the ability of the 'excluded' to handle the institutional encounters whose exclusions, impositions, costs and failures constitute so much of their initial experience. A shorthand term for that area is mobilised participation, but it is scarcely an area for direct prescription here ${ }^{12}$. One prescriptive question is whether that sort of dimension has any implications for processes of institutional evaluation and administrative planning themselves: the answer is, I think, positive. In any case, political appeals around basic needs and the demands made by choices for basic needs on decision-making processes are complex. The concern with ideas of a minimum is long and complex too: Marx, Nassau Senior and Beveridge are a mixed heritage. The Beveridge ideas remain fertile, but the grounds of institutional action then have to be traversed. The largest question is how that is to be done.

12 Schaffer, 1977 , p. 55 ; of. S. P. Huntington and J. M. Nelson, No Easy Choice, Harvard, 1976.

\section{Erratum}

'Class Formation and Antediluvian Capital in Bangladesh' Geof Wood

In our last issue (Vol 9 no 3) p $40 \quad 1 \quad 12$ should read:

It is another question whether these relations are a temporaary phase of early accumulation destined to transform the social formation into mature capitalism (Chattopadhyay 1972); or whether they are bound to persist and stunt the development of capitalist relations in Bangladesh (Patnaik 1972; Alavi 1975). 